\title{
Factors Influencing Social Media Choice for Product Promotion Among Small and Medium-Sized Enterprises in Tanzania
}

\author{
Salimu Abushiri Jinyevu $^{1^{*}} \quad$ Cheng Yanxia $^{1} \quad$ Eric Mwanga Balama $^{1} \quad$ Jamila Rashid Ng'itu $^{2}$ \\ 1. School of Management, Wuhan University of Technology, Wuhan, P.R. China,430070 \\ 2. Shandong University, Jinan, P.R. China
}

\begin{abstract}
The paper focuses on examining factors which influence the selection of Social Media among small and mediumsize enterprises (SMEs) in Tanzania. This study assesses the influence of product, resources, target audience, on social media selection. The study based on company perspective which makes it so unique since many studies focused on consumer perspective. The primary data of the study were collected through self-monitored questionnaire from 197 respondents among 15 SMEs in Tanzania mainland only. Moreover, secondary data were obtained from literature such as journals, books, and websites. Interview and observation were used to enrich data collection process. The study data were analyzed using SmartPLS 3.0 and SPSS software version 22. Structure equation modeling was applied as the main research methodology of the study. Findings show that both resources and product have direct positive influence on social media while target audience shows a positive significant influence on social media. Lastly product found to have positive significant influence on target audience. The study recommends SMEs to do a survey and segmentation of the social media users in order to know the characteristics of their target audience so as to be able to choose social media type which match target audience. Other managerial implication related to product, and resources have also been suggested. The study conclude that, there is no one right social media for all products and all audience but SMEs need to choose social media based on the strength of the characteristics of the product, audience and the resources available/needed such as budget and skilled staff
\end{abstract}

Keywords: Product, Resources, Target Audience, Social Media

DOI: $10.7176 / \mathrm{JESD} / 10-20-08$

Publication date:October $31^{\text {st }} 2019$

\section{Introduction}

Social media has become a new product promotion vehicle to many small and medium enterprises across the globe. Currently many social media platforms are emerging on daily basis. For example, social networking sites are of many types such as Facebook, Twitter, Instagram, WhatsApp, Viber to mention few. Because many social media are emerging every day, choosing the right social media becomes a very challenging task among small and medium-sized enterprises. What is important to advertisers is the media selection because each media is difference from the other due to the different features each media has (Chaudhur and Buck, 1995). On choosing the right social media, Bullas (2018) emphasizes that among the biggest mistake which small business owners make is to see social media as homogenous entity. Facebook, Snap Chat, Twitter, WhatsApp and Instagram are all types of social networks but they have a big different from audience, the makeup and the style are unique, therefore the concern is that how can SMEs insure that the social media they chose is right in achieving their goals? This paper aim at examining factors which influence the selection of social media for product promotion in order to create better understandings to SMEs managers on the selection of right and effective social media.

\section{Review of Literature}

SMEs use social media as a new vehicle to communicate with their customers. In order for the promotional message to be delivered successfully, small and medium-sized enterprises have to choose social media channel correctly due to the fact that currently there is mushrooming of social media platform with different features. This study discusses few selected factors which determine the choice of social media, including product, resources, target audience and social media.

\subsection{Product}

Kotler \& Armstrong, (2012) define product as anything which can be offered to a market for the purpose of making attention, acquisition, use, consumption in order to satisfy needs or wants. Products fall under two main categories mainly consumer products and industrial products (Kotler \& Armstrong, 2012). Consumer products refer to products which are bought for personal consumption by final consumer. Consumer products differ from one another depending on how consumers buy them as well as how they are marketed by the SMEs. On another hand, Industrial products are the kind of products which are bought in order to be processed or for business purpose. Therefore, the main distinction between consumer products and industrial products rely on the purpose of which the product is purchased by a customer. Since the purpose and the buyer of the products differ, also how the 
particular product is marketed and promote differ. In marketing any among the product classes, the media channel which match particular product group is very important (Jinyevu, 2018). Promoting a consumer product on social media, requires a right social media where consumers of that products are available, so do industrial products.

Therefore, the study hypothesizes that;

H1: Type of product has a significant positive influence on the choice of social media for product promotion.

On another hand, product plays a crucial role in determining the audience type. The kind of product to be promoted must consider the kind of customers on social media who acts as their target market.(Jinyevu, 2018) Therefore this study hypothesize that

$\mathrm{H} 2$ : Product has significant positive influence on target audience

\subsection{Resources}

For a successful selection of right social media, resources are needed. Resources include budget allocation and skilled human resources who create the content from SMEs side, engage and interact professionally with social media users. As suggested by Vinerean (2017) that organizations need to allocate all necessary resources in order to manage their online presence because Wang and Kim (2017) emphasize that companies that are more active on social media are in a good position to improve their value even more among the crucial resource is budget which SMEs allocate in order to promote products and services on chosen social media using different promotion strategies such as content marketing strategies, social media endorsement, sponsored ads etc as Morrison (2017) and Vinerean (2017) explain that companies allocates budget to promote products and brands through social media influencer marketing strategy. Moreover, skilled human resource is another resource which SMEs need in order to successful use different social media tools available as well as communicate properly with different social media users who have difference characteristics. Paid ads need budget (Jinyevu, 2018), it is the budget which determine the type of social media to run sponsored ads advertisement. Low or no allocation of budget will only allow managers to access free social media tools, therefore;

H3: Resource significantly influence the choice of social media

\subsection{Target Audience}

Sissors and Baron (2010) refer to target audience as people or group of people whom the advertisement message tries to influence them. On discussing the target audience, Klososky (2011) focused on the volume of the target audience and the acceptability of the chosen media to the target audience. In another word, SMEs when selecting social media platform, they are required to consider how many people are using the particular social media because these people are the target audience of the SMEs and their number (volume) tells all about how that particular SMEs is accepted by them. Moreover, SMEs supposed to define the audience they target to reach in order to communicate with using right social media channel (Effing \& Spil, 2016). The target audience may include various stakeholders, culture and group such as experts as well as generation X or Y. Target audience are described according to their basic demographic characteristics like age, gender, economic status and geographical location in order to select the right social media. Therefore, the study hypothesizes that;

H4: Target Audiences have positive significant influence on the choice of social media

\subsection{Social Media}

Kaplan and Haenlein (2010) describe social media as as applications available on internet which allow users to develop, consume and share their content. As explain by Filo et al (2015) social media is characterized by interactivity and co-creation of user-generated content in the relationship brought about between company and a person. Social media plays essential role in connecting products, brands, services with consumers and organizations (Vinerean, 2017). Social media are of different types and features which distinguishes one another. This study adopted Mangold and Faulds (2009) categorization of social media, however only four categories will be used in this study namely social networking site such as Facebook, Instagram etc, video sharing site such as YouTube etc., Company sponsored website and commerce communities. Klososky (2011) mentioned several characteristics that SMEs marketing managers have to take into consideration when selecting type of social media as their marketing strategy, these includes the functionality of the tools of the selected social media, ease of use of the particular social media, data standard, security and privacy characteristics. Therefore different types of social media are unique in terms of structure, functions/usage, resources needed to operate and type of audience subscribed in that particular social media.

\section{Conceptual Model}

The conceptual model derived from the review of literature. The model have three variables namely product, resources, target audience and social media. The model also shows the relationship between selected variables 


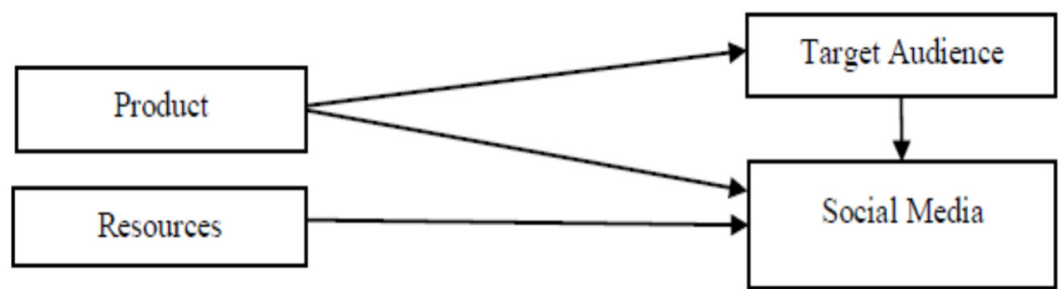

Figure 1: Conceptual Model

\section{Methodology}

\subsection{Collection of Data}

The data for this study, collected through self-monitored questionnaire from marketing managers and staff of small and medium enterprises as a source of primary data, while secondary data were collected from different related literature including academic journals, papers, books, websites and other online relevant materials. The distribution of questionnaires was both online and physically. Interview with some managers and staff of SMEs were also conducted as well as observation method.

\subsection{Population of Study and Sample Selection}

The population of this study is from Tanzania mainland and involves managers and staffs working at the Small and Medium Enterprises particularly in the marketing department. All SMEs selected were from urban area because at the urban area more SMEs are likely to use social media than in rural area where the internet connectivity is very small or no internet at all.

\subsection{Data analysis Techniques}

In order to analyze data, the study uses SPSS software 22.0 and SmartPLS 3.0. Several statistical analyses were performed including mean, frequency, percentage, validity, reliability. The main methodology of the study is structure equation modeling.

\section{Findings and Discussion}

\subsection{Sample Composition}

250 questionnaires were distributed among 250 Respondents from 20 SMEs however its only 197 questionnaire were returned back, making $78.8 \%$. The analysis of demographic data was done through SPSS 22 , the analysis show that there is no missing data as total number of all items in questionnaire 197 . The analysis based on respondents' gender, level of education, social media using and position at the SMEs. Table 1 show the finding of demographic details of respondents

Table 1: Demographic Details

\begin{tabular}{|c|c|c|}
\hline Characteristics & Frequency (f) & Percentage $(\%)$ \\
\hline $\begin{array}{ll}\text { Gender: } & \text { A) Male } \\
& \text { B) Female } \\
& \text { Total }\end{array}$ & $\begin{array}{c}89 \\
108 \\
197\end{array}$ & $\begin{array}{l}45.2 \\
54.8 \\
100.0\end{array}$ \\
\hline $\begin{array}{c}\text { Level of education } \text { A) Undergraduate } \\
\text { B) postgraduate } \\
\text { C)Non-degree } \\
\text { Total } \\
\end{array}$ & $\begin{array}{c}149 \\
37 \\
11\end{array}$ & $\begin{array}{c}75.6 \\
18.8 \\
5.6 \\
100.0 \\
\end{array}$ \\
\hline $\begin{array}{ll}\text { Social media usage: } & \text { A) Yes } \\
& \text { B) No } \\
& \text { Total } \\
\end{array}$ & $\begin{array}{c}197 \\
0 \\
197 \\
\end{array}$ & $\begin{array}{l}100.0 \\
0 \\
100.0 \\
\end{array}$ \\
\hline $\begin{array}{l}\text { A) Staff } \\
\text { B) Leader/Manager } \\
\text { Total }\end{array}$ & $\begin{array}{c}185 \\
12 \\
197\end{array}$ & $\begin{array}{c}93.9 \\
6.1 \\
100.0\end{array}$ \\
\hline
\end{tabular}

\subsection{Evaluation of the Model Measurements}

The model measurement applied to explain the relationship between latent variable and observed variables. Both validity and reliability were calculated. The study also used confirmatory analysis in order to test the relationship of the model between latent variables as well as measure variables with indicators of common factors (Suhr, 2008) 5.2.1 Construct Validity

Using SPSS 22 software the Kaiser-Meyer-Olkin of Sampling Adequacy as well as Bartlett's Test of Sphericity was calculated in order to measure appropriateness of factor analysis (Field, 2009). It ranges from 0-1. The value 
greater than 0.5 is regarded as significant, while 0.5-.07 is interpreted as mediocre, 0.7-0.8 is good, 0.8-0.9 greater and above 0.9 is superb (Haier et al, 1992). The finds in Table 2 show that Kaiser-Meyer-Olkin value is 0.945 which is superb, therefore very appropriate for the use of the study. Moreover, the Bartlett's Test of Sphericity indicates high significance since $\mathrm{p}<0.05$, therefore support the appropriateness of the factor analysis related with this study.

Table 2: KMO and Bartlett's Test

Kaiser-Meyer-Olkin Measure of Sampling Adequacy. Bartlett's Test of Sphericity Approx. Chi-Square

df

2016.224

Sig.

Construct validity as well as descriptive validity performed purposely to estimate how valid the construct are.

5.2.2 Validity Test

This study used Average Variance Extracted (AVE) in order to describe an average variation that latent variable ability to explain in observed variables to which theoretically is associated with (Farrel, 2009). According to Fornell and Larker, (18981) construct validity is regarded as sufficient when AVE value is greater than 0.5 which means $50 \%$ of the variation within the entire scale indicator. Table 3 indicates the construct validity range from 0.696 to 0.724 which is greater than 0.5 therefore it within the suggested range

Table 3: Construct Reliability and Validity

\begin{tabular}{|l|l|l|l|l|}
\hline & $\begin{array}{l}\text { Cronbach's } \\
\text { Alpha }\end{array}$ & $\begin{array}{l}\text { rho_ } \\
\text { A }\end{array}$ & $\begin{array}{l}\text { Composite } \\
\text { Reliability }\end{array}$ & $\begin{array}{l}\text { Average Variance Extracted } \\
\text { (AVE) }\end{array}$ \\
\hline Product & 0.799 & 0.802 & 0.881 & 0.713 \\
\hline Resources & 0.810 & 0.819 & 0.887 & 0.724 \\
\hline Social Media & 0.782 & 0.782 & 0.873 & 0.696 \\
\hline $\begin{array}{l}\text { Target } \\
\text { Audience }\end{array}$ & 0.798 & 0.810 & 0.881 & 0.712 \\
\hline
\end{tabular}

\subsubsection{Reliability Test}

To measure reliability the Cronbach's Alpha was used as a measure of internal consistency. Cronbach's Alpha range from 0-1, the higher the value the higher the consistency (Cohen et al, 2007). The value of 0.70 is assumed as suitable internal consistency, but 0.6-0.70 is reasonable (Cohen, et al, 2007) while less than 0.6 is assumed as lack of reliability. Table 3 show the Cronbach's Alpha of the study, which ranges from $0.782-0.810$ that is greater than the suggested value of 0.7

\subsection{Structure Equation Modeling}

\subsubsection{The Goodness of Model Fit}

It was calculated for the purpose of validating a partial least square path model through validating the overall prediction performance of both inner and outer model. The standardized Root Mean Score Residual (SRMR) was used to measure appropriate model fit index, where by te value less than 0.1 is suggested as the appropriate fit index (Haier et al, 2012). Table 4 indicates the results of the study where SRMR value is 0.076 for saturated model which is less than 0.1

Table 4: Evaluation of the Goodness of Model Fit

\begin{tabular}{|c|c|c|}
\hline Fit Criteria & Saturated Model & Estimated Model \\
\hline SRMR & 0.076 & 0.111 \\
\hline
\end{tabular}

5.3.2 Evaluation of Coefficient of Determination $\left(R^{2}\right)$

In order to evaluate the inner model , R square was calculated. Chin (1998) suggest that $R$ square value of around $1.9,0.33$ and 0.67 are regarded as weak, moderate and substantial. The $\mathrm{R}$ square value of the study constructs is shown on Table 5, which indicates 0.638 for social media and 0.513 , which all are moderate values. This interpreted that the variables explain specifically $63.8 \%$ and $51.3 \%$ variation in social media and target audience. Also, figure 2 shows semPLS algorithm of structure model of this study.

Table 5: Results of $\mathrm{R}^{2}$ and Adjusted $\mathrm{R}^{2}$

\begin{tabular}{|l|l|l|}
\hline & R Square & R Square Adjusted \\
\hline Social Media & 0.638 & 0.632 \\
\hline Target Audience & 0.513 & 0.511 \\
\hline
\end{tabular}




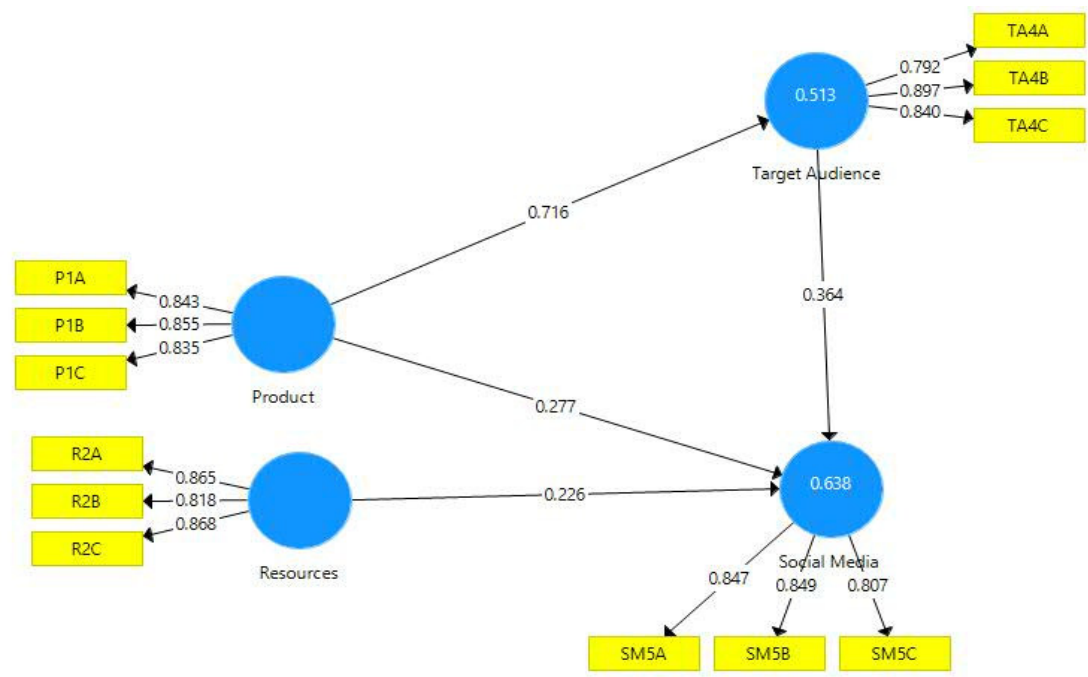

Figure 2: semPLS Algorithm Structure Model

$\mathrm{P}=$ Product, $\mathrm{R}=$ Resources, $\mathrm{TA}=$ Target Audience, $\mathrm{SM}=$ Social Media

\subsection{Hypothesis Testing}

Hypothesis testing was performed through bootstrapping results by using semPLS 3.0 Standard error and tstatistics were calculated and it is significant at the level 0.05 when the t-statistics is great than 1.96 and at 0.01 when $t$-statistic is higher than 2.58 , also at the 0.001 when the value is higher than 3.29 . The result from the study is shown in Table 6 through findings of standard path coefficient and the significant value used in hypothesis testing. All hypothesis of the study accepted. Furthermore, the study performed semPLS bootstrapping of Structure Model, which shown in figure 3 below

Table 6: Path Coefficients Results

\begin{tabular}{|l|l|l|l|l|l|l|l|}
\hline Hypothesis & & $\begin{array}{l}\text { Original } \\
\text { Sample (O) }\end{array}$ & $\begin{array}{l}\text { Sample } \\
\text { Mean (M) }\end{array}$ & $\begin{array}{l}\text { Standard } \\
\text { Deviation } \\
\text { (STDEV) }\end{array}$ & $\begin{array}{l}\text { T Statistics } \\
(\mid \mathbf{O} / \text { STDEV|) }\end{array}$ & P Values & Decision \\
\hline H1 & P -> SM & 0.277 & 0.274 & 0.072 & 3.871 & 0.000 & Accepted \\
\hline H2 & P -> TA & 0.716 & 0.717 & 0.043 & 16.470 & 0.000 & Accepted \\
\hline H3 & R -> SM & 0.226 & 0.237 & 0.110 & 2.052 & 0.041 & Accepted \\
\hline H4 & TA-> SM & 0.364 & 0.358 & 0.103 & 3.539 & 0.000 & Accepted \\
\hline
\end{tabular}

Notes: $\mathrm{P}=$ Product, $\mathrm{R}=$ Resources, $\mathrm{TA}=$ Target Audience, $\mathrm{SM}=$ Social Media

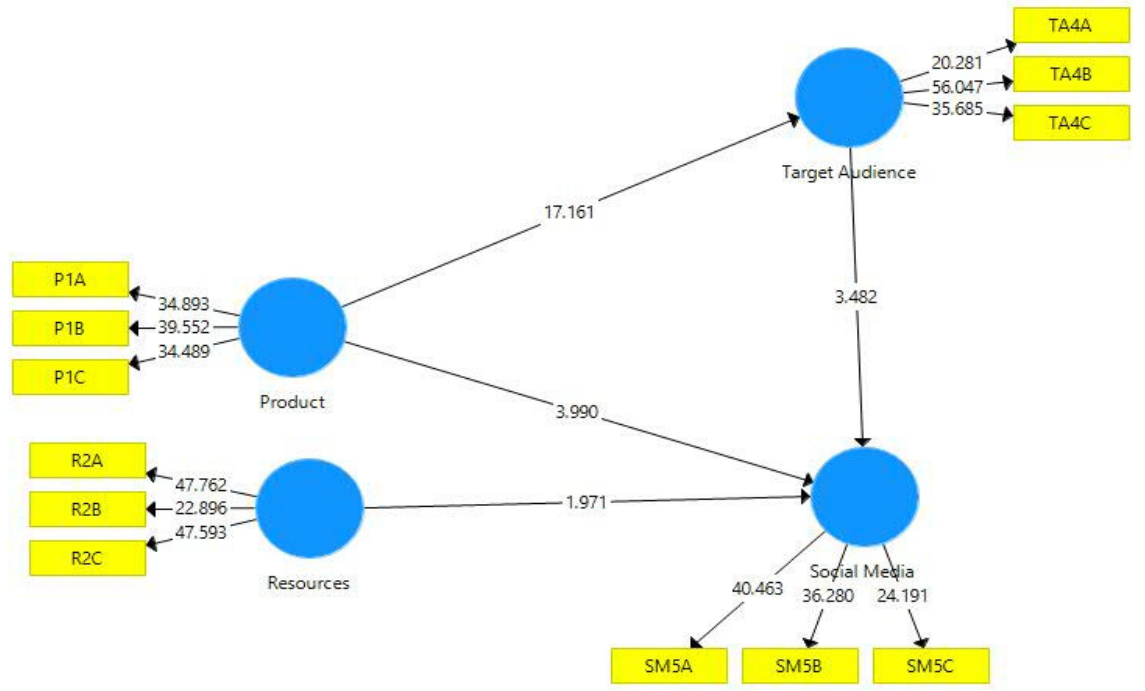

5.4.1 The Influence of Product on the Choice of Social Media

With reference from table 6 , the results indicates that product has a very high positive significant influence on the choice of social media type ( $\mathrm{t}$-value $3.871, \mathrm{P}<0.001$ ) hence $\mathrm{H} 1$ accepted. The type of product SME wish to promote dictated the type of social media to be used to advertise particular product. SMEs need to identify characteristics of social media which they plan to advertise in order to determine what kind of of product best fit the social media type. Consumer products determine the type of social media to be used which are likely to have consumers of that 
product category than industrial products. Also industrial products fit more to be promoted on social media which have users interested on industrial products.

5.4.2 The Influence of Product on Target Audience

The findings of the study indicates that product has very high positive significant influence on target audience ( $\mathrm{t}-$ value $16.470, \mathrm{P}<0.001$ ), hence $\mathrm{H} 2$ accepted. Every product are specifically for particular type audience. For example when SMEs pay for sponsored ads on Facebook, they must select some demographic characteristics of the target audience such as age range and location in order to make sure that the product promoted reach the correct audience and the promotion campaign goal is reached because it's not all product for everyone. Specific product for specific audience hence product influence the target audience which are social media users.

5.4.3 The Influence of Resources on the Choice of Social Media

The result of the study show that resource has high positive significant influence on the choice of social media ( $t$ value 2.052, $\mathrm{P}<0.05$ ) therefore, $\mathrm{H} 3$ accepted. This means that what the company have in terms of budget resource and technical knowhow influence largely on the choice of the type of social media for product promotion. SMEs staffs responsible for social media need to be well knowledgeable about how the selected social media is working and how to use its promotion features to promote product and engage professionally with social media users. Hence the knowledge and experience the employee have on selected social media have positive influence on the type of social media to be selected. Furthermore, each social media have specific charges when it comes on paid advertisement such as sponsored adds, online advertising etc, hence the budget allocation determines which social media to be selected. Also the relative cost of each promotion campaign determines the type of social media to be used. Hence budget, relative cost and skilled employees are important resources which influence the choice of social media.

\subsubsection{The Influence of Target Audience on the Choice of Social Media}

The study find out that Target audience has a very high significant influence on the choice of social media (t-value $3.539, \mathrm{P}<0.001$ ), this means that $\mathrm{H} 4$ is supported, this findings also support the study by Effing and Spil (2016). Different people choose different social media due to usability, functionality and popularity of a particular social media. Example, in Tanzania some use WhatsApp because of its ability to send Pdf files while in Instagram they cannot, while others use Facebook due to its popularity and large number of users hence easy to communicate with many friends, relatives, business etc. When SMEs select social media type, need to consider to what extent the particular social media is widely used and accepted by many target audience. Moreover, the demographic details of target audience such as gender age and economic status influence the selection of social media channel. Effing and Spil (2016) suggest that SMEs must define and analyse the type of audience they wish to communicate. Young customers uses more Instagram than Facebook, while aged people use Facebook more than Instagram, Academician and experts uses LinkedIn, politicians, leaders, celebrities uses Twitter more. Therefore SMEs must select social media type by considering the characteristics of their target audience.

\subsection{Managerial Implication}

SMEs marketing managers should consider different products for different audience of social media. Depending on characteristics of the product, some products fits more a certain audience in one of SMEs social media channel than other channel, therefore managers should not assume that they can promote any product in any social media account they possess. A product can be suitable to SME audience in Twitter but the same product cannot be appropriate to Facebook audience of the same SME. Product must be well chosen according to the matching characteristics of the social media users who are the target audience of the SME

In terms of resources, SMEs should select social media platforms of which their SMEs are conversant with, in order to make sure that they engage and interact with target audience in a professional manner. Skilled employees perform better than unskilled. Managers should arrange routine training to their SMEs so that they can a wider chance of professionally accessing many social media of their choice, which eventually will help in reaching more target audience. SMEs should allocate enough budget to different social media in order to have a wider range in choosing and accessing different social media according to the need. Insufficient or not allocating budget necessitates SMEs to choose social media types which provide free promotion tools (organic reach only) but for paid tool (paid reach) SMEs will have small or no access. Moreover, the allocation should be correctly done, miss allocation of budget to wrong social media platform is a burden to SME and hence the promotion goals cannot be reached.

In order to understand the target audience characteristics, SMEs managers should do survey and make segmentation of their audience according to the social media they are available. Proper understanding of audience insures proper selection of social media platform as well as proper placement of promotion advertisement on a particular social media. Audiences are not homogeneous, but rather they are of different a demographic characteristic that makes each group unique, hence engaging and interacting with them needs is different. 


\section{Conclusion}

There is no one single perfect social media for every product and for every target audience, what works in one business, does not necessarily have to work in another business because social media are heterogeneous in nature. Therefore, Small and medium-sized enterprises need to select different social media depending on the resources they have and characteristics of audience and product they promote.

Future research can be done to include more factors such as security, prior experience, content etc and a wider sample in order to enhance understandings on how SMEs in Tanzania can correctly select social media for product promotion.

\section{References}

Baker, M. (2003). The Marketing Book Fifth Edition. London: Butterworth Heinemann

Bullas, J (2018) The ultimate guide to social media marketing (Online). Retrieved $27^{\text {th }}$ September, 2019. Available: https://www.jeffbullas.com/social-media-marketing-guide/

Chin ,W.W.(1998) The Partial least square approach to structure equation modeling in: Marcoulides, G.A (Ed), Modern methods for business research. Lawrence Erlbaum Associates, New Jersy, 1998.

Cohen, L., Manion,L and Morrison, K.(2007) Research Method in Education. Six Edition, Routledge.

Constantine, D. (2013) The social media and organization performance among civil society. Organization in Tanzania. Dissertation for Award of M.A Degree at University of Dar-es-salaam: Tanzania, 73.

Farrel A.M.(2009). Insufficient Discriminant Validity : A comment on Bove, Pervan, Beatty and Shiu. Journal of business Research 63(3) 324-327

Field, A.P. (2009) Discovering statistics using SPSS:sex and drug and rock'n Roll, $3^{\text {rd }}$ edition. London:Sage

Filo, K., Lock, D. and Karg, A., (2015). Sport and social media research: A review. Sport Management Review, 18 (2), pp.166-181

Fornell, C. and Larcker, D.F. (1981). Evaluating Structure Equation Models with an observable variables and Measurement error, Journal of Marketing research, 18(1), 39-50

Hackley, C. (2005) Advertising \& Promotion: Communicating Brands . Sage publications

Haier ,J.F., Anderson, R.E., Tatham, R.L., and Black, W.C. (1992). Multivariate Data Analysis with Readings . Prentice Hall.

Haier, J.F., (2012) Sarstedt M, and Ringle C.M. The use of Partial lest squares structural equation modeling in strategic management research: A review of past practice and commendations for future applications. Long Range planning, 45 (5) 320-340

Jinyevu, S.A., Mkonya,V.L., Dantur, M.L (2018) "Exploring the use of consumer endorser strategy in social media product promotion advertisement and its impacts on young consumers behavior in Tanzania". Proceedings of the 15th international conference on innovation and management, Wuhan University of Technology press, 2, 764-770

Kaplan, A.M. and Haenlein, M., (2010). Users of the world, unite! The challenges and opportunities of Social Media. Business Horizons, 53 (1), pp.59-68

Klososky, S. (2011) Manager's guide to social media. New York, The McGraw-Hill Companies, 2011

Kotler, P., \& Armstrong, G.(2012). Principles of Marketing 14th edition. [B] New Jersey: Pearson Education, Inc.

Morrison, K.,( 2017). Influencer Marketing Is Becoming an Essential Business Strategy (Survey) [online] Available at: http://www.adweek.com/digital/influencer-marketing-is-becoming-an-essentialbusinessstrategy-survey/ [Accessed on 9 May 2017]

Paquette, H. (2013) Social media as a marketing Tool: A literature Review. Major papers by Master of Science Studies. Paper 2.

Ringle, C. M., Wende, S., and Becker, J.-M. 2015. "SmartPLS 3." Boenningstedt: SmartPLS GmbH, http://www.smartpls.com.

Sissors, J.Z and Baron, R.B (2010). Advertising Media Planning Seventh Edition. New York, McGrawHill

Suhr D,(2008) Step your way through path analysis. In western users of SAS software conference proceedings.

Tritama, HB and Tarigan,R.E. (2016). The Effect of Social Media to the Brand Awareness of a Product of a Company. CommIT Journal, vol. 10, no. 1, 9-14.

Vinerean, S. (2017). Importance of Strategic Social Media Marketing. Expert Journal of Marketing, 5(1), 28-35. 